\title{
PREDIKSI PENJUALAN OBAT HERBAL HP PRO MENGGUNAKAN ALGORITMA NEURAL NETWORK
}

\author{
Dwi Agung Wibowo \\ Fakultas Teknologi Informasi \\ Universitas Islam Kalimantan Muhammad Arsyad Al Banjari Banjarmasin \\ e-mail:agungfti@gmail.com
}

\begin{abstract}
ABSTRAK
Sistem prediksi adalah sebuah perangkat untuk mendukung aktifitas manusia.Setiap tempat dapat dilihat bahwa untuk memutuskan sesuatu manusia memerlukan hasil prediksi. Terdapat beberapa perangkat prediksi yang dikembangkan dan diteliti. Dari waktu kewaktu kerumitan dan kemampuannya semakinmeningkat.Prediksi tidak hanya dimiliki oleh ahli matematika yang memiliki kemampuan matematis. Saat ini prediksi digunakan oleh manusia di berbagai latar belakang pengetahuan dan pekerjaan Pada area ekonomi, terdapat beberapa alat untuk melakukan prediksi sesuatu yang berkaitan dengan parameter maupun variable ekonomi, seperti bursa efek, inflasi, pertumbuhan ekonomi, pertukaran nilai kurs dll.

Seringkali prediksi dilakukan untuk mendukung penyusunan Anggaran Belanja NegaraPada level perusahaan, prediksi memegang peran yang penting untuk perencanaan dan evaluasi. Salah satu prediksi yang penting adalah prediksi penjualan. Dari hasil prediksi ini, perusahaan dapat merencanakan produksi, strategi pemasaran dan anggaran. Tetapi dengan meningkatnya kompleksitas perusahaan(persaingan, perubahan budaya, perubahan lingkungan dll) akan mempengaruhi hasil prediksi dan dapat mengurangi akurasi dan menambah kesalahan prediksi.Untuk itu, saat ini diperlukan system prediksi yang baru, yang memiliki kemampuan untuk beradaptasiterhadap perubahan.

Berbicara tentang adaptasi, terdapat perangkat adaptasi yang sangat menarik yang dikembangkan oleh ahli sistem kendali. Perangkat adaptasi ini adalah algoritma neural network yangdapat digunakan sebagai prediksi penjualan.
\end{abstract}

Kata kunci: penjualan, jaringan saraf tiruan prediksi rentet waktu,Mean Squard Error (RMSE) 
PENDAHULUAN

Latar Belakang Masalah

Pada persaingan usaha saat ini menuntut pengusaha agar lebih peka tehadap keinginan dan kebutuhan konsumen akan produk yang ditawarkan. Sehingga perlu adanya manajemen yang berperan dalam menentukan jumlah penjualan. Keberhasilan suatu perusahaan dicerminkan oleh kemampuan perencanaan dalam manajemen untuk memanfaatkan peluang secara optimal sehingga dapat menghasilkan penjualan dan laba sesuai yang diharapkan.

Prediksi adalah suatu usaha untuk meramalkan keadaan dimasa mendatang melalui pengujian keadaan dimasa lalu. Meramalkan penjualan berarti menentukan perkiraan besarnya volume penjualan, bahkan menentukan mengambil keputusan atau kebijakan sesuai dengan hasil prediksi penjualan tersebut, sebelum penelitian ilmiah ini dilakukan potensi penjualan dan luas pasar yang dikuasai dimasa yang akan datang.

Dengan adanya kegiatan prediksi penjualan ini dapat mengambil keputusan atau kebijakan sesuai dengan hasil prediksi penjualan tersebut, sebelum penelitian ilmiah ini dilakukan. Karena dengan pemilihan dan penggunaan metode yang tepat, maka keberhasilan perusahaan dalam menawarkan produknya akan dirasakan dalam bentuk laba yang didapatkan. Penulisan ilmiah ini juga akan memberikan perbandingan penggunaan metode yang memiliki kesalahan terkecil, sehingga perusahaan dapat mengaplikasikannya dalam manajemen perusahaan. Prediksi penjualan juga dilakukan untuk bias terus memenuhi kebutuhan pelanggan yang dilihat dari hasil prediksi agar manajer dapat memperhitungkan stock persediaan.

Keberhasilan yang dicerminkan oleh kemampuan perencanaan dalam manajemen untuk memanfaatkan peluang secara optimal sehingga dapat menghasilkan penjualan dan laba sesuai dengan yang diharapkan serta untuk menghindari resiko yang tidak diinginkan sehingga dapat yang mencapai suatu keuntungan. Karena dalam hal ini prediksi penjualan merupakan pendekatan yang berbasis dengan memperhitungkan resiko yang mungkin akan terjadi dimasa yang akan datang. Dengan itu naik turunnya penjualan yang dicapai dapat dipergunakan sebagai alat ukur maju mundurnya usaha.

Pada penelitian ini penulis ingin memprediksi penjualan obat herbal Hp Pro berdasarkan data-data penjualan yang terdahulu,data yang dimiliki merupakan data penjualan harian tahun 2009 hingga 2013. sehingga bisa memberikan prediksi yang akurat pada penjualan tahun-tahun kedepan.Hp Pro merupakan obat herbal yang berfungsi untuk mengurangi inflamasi / peradangan pada liver/ hati.

Metode yang digunakan untuk melakukan peramalan sangatlah beragam.salah satu metode yang sering dilakukan dalam peramalan penjualan adalah dengan metode time series.Dalam metode time series sendiri terdapat beberapa cara yang digunakan,dalam penelitian ini akan dicoba untuk melakukan peramalan time series dalam penjualan dengan menggunakan metode Neural Network bertujuan untuk mengidentifikasi variabel yang sama pentingnya dalam data set,kemudian $m$ embuang variabel lain yang nilainya tidak relevan dan berlebihan.pemilihan variabel dapat mengurangi pemakaian data,hal ini memungkinkan lebih efektif dalam operasi yang lebih cepat sehingga memungkinkan dapat meningkatkan akurasi data. Neural 
network atau lebih dikenal dengan Artificial Neural Network sebagai cabang dari ilmu kecerdasan buatan (artificial intelligence), merupakan salah satu sistem pemrosesan informasi yang didesain dengan menirukan cara kerja otak manusia dalam menyelesaikan suatu masalah Alexander dan Morton mendefinisikan $N N$ sebagai prosesor paralel tersebar yang sangat besar, yang memiliki kecendeungan untuk menyimpan pengetahuan yang bersifat pengalaman dan membuatnya untuk siap digunakan.

\section{Rumusan Masalah}

Dari penjelasan diatas, maka penulis merumuskan permasalahan yaitu:

1. Berapa besar prediksi penjualan pada tahun 2014 dan seterusnya.

2. Bagaimana meningkatkan akurasi prediksi penjualan menggunakan metode Neural Network.

\section{Tujuan Penelitian}

Tujuannya adalah menghasilkan sebuah akurasi data untuk predikisi penjualan dengan memakai metode neural network berdasarkan data-data yang terdahulu.

\section{Manfaat penelitian}

\section{Manfaat Praktis}

Penelitian ini diharapkan bermanfaat bagi :

1. Bagi bidang keilmuan, melalui pengembangan metode Neural Network chisquared diharapkan dapat menambah metode prediksi dalam bidang penjualan.

2. Bagi PT. Mitra Barito Simber Sejahtera, penggunaan metode Neural Network diharapkan dapat meningkatkan akurasi prediksi penjualan.
Prediksi adalah suatu usaha untuk meramalkan keadaan dimasa mendatang melalui pengujian keadaan dimasa lalu. Meramalkan penjualan berarti menentukan perkiraan besarnya volume penjualan, bahkan menentukan mengambil keputusan atau kebijakan sesuai dengan hasil prediksi penjualan tersebut, sebelum penelitian ilmiah ini dilakukan potensi penjualan dan luas pasar yang dikuasai dimasa yang akan datang.

\section{Data Mining}

Data mining merupakan data yang tersimpandalam waktu yang lama kemudian data tersebut dikumpulkan, ternyata setelah di analisis data tersebut memiliki pola tertentu. Data mining biasanya berisi tentang statistik, ekonomi, ramalan cuaca serta berbagai jenis data lainnya yang berhubungan dengan pekerjaan. Data mining merupakan pelajaran apa yang telah terjadi dimasa lalu kemudian akan diterapkan dimasa yang akan datang agar memperoleh hasil yang lebih baik. Secara khusus, koleksi metode yang dikenal sebagai data mining menawarkan metodologi dan solusi teknis untuk mengatasi analisis data medis dan konstruksi prediksi model.

\section{Penjualan}

Penjualan merupakan suatu transaksi yang dilakukan oleh dua belah pihak atau lebih dengan menggunakan alat pembayaran yang sah, dengan penjualan juga merupakan salah satu sumber pendapatan seseorang atau perusahaan yang melakukan transaksi jual dan beli, dalam suatu perusahaan apabila semakin besar penjualan maka akan 
semakin besar pula pendapatan yang diperoleh.

\section{Neural Network}

Neural network atau lebih dikenal dengan Artificial Neural Network sebagai cabang dari ilmu kecerdasan buatan (artificial intelligence), merupakan salah satu sistem pemrosesan informasi yang didesain dengan menirukan cara kerja otak manusia dalam menyelesaikan suatu masalah. Alexander dan Morton mendefinisikan $N N$ sebagai prosesor paralel tersebar yang sangat besar, yang memiliki kecendeungan untuk menyimpan pengetahuan yang bersifat pengalaman dan membuatnya untuk siap digunakan.Lebih lanjut dijelaskan bahwa $N N$ dibentuk sebagai generalisasi model matematika dari jaringan syaraf biologi dengan asumsi: pemrosesan informasi terjadi pada banyak elemen sederhana (neuron); sinyal dikirimkan diantara neuron-neuron melalui penghubung-penghubung; penghubung antar neuron memiliki bobot yang akan memperkuat atau memperlemah sinyal; dan untuk menentukan output setiap neuron menggunakan fungsi aktivasi yang dikenakan pada jumlahan input yang diterima, besarnya output ini selanjutnya dibandingkan dengan suatu batas ambang. Dengan demikian $N N$ ditentukan oleh tiga hal, yaitu: pola hubungan antar neuron (disebut arsitektur jaringan); metode untuk menentukan bobot penghubung (disebut metode training/ learning/ algoritma); dan fungsi aktivasi.

$N N$ telah banyak diaplikasikan dan sangat sukses digunakan untuk memecahkan berbagai masalah dalam berbagai disiplin ilmu seperti bidang komputer, teknik, ilmu murni, perdagangan, financial dan lain-lain.

Menurut Siang banyak model $N N$ menggunakan manipulasi matriks/ vektor dalam iterasinya, dan RAPIDMINER5 menyediakan fungsi-fungsi khusus untuk menyelesaikan model $N N$. User tinggal memasukkan vektor masukan, target, model, dan parameter yang diinginkan yaitu laju pemahaman, threshold, dan bias.

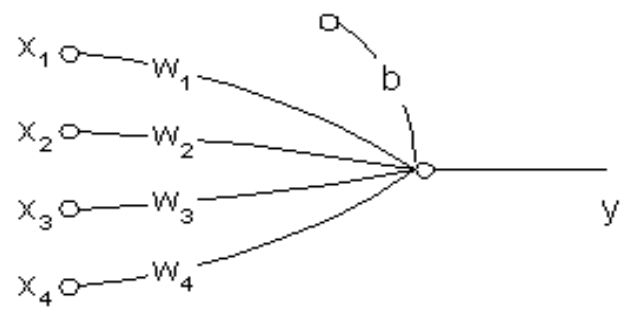

Gambar 1 Model Algoritma Satu Layer

\section{METODE PENELITIAN}

Metode enelitian

Metode penelitian yang dilakukan adalah metode penelitian eksperimen, dengan tahapan penelitian

dalam skema penelitian seperti berikut:

- Metode Pengumpulan Data

DataGathering)

- Metode Pengolahan Data Awal (Data Pre- processing)

- Metode yang Diusulkan (ProposedMethod)

- Eksperimen dan Pengujian Method/Model(Metode Test and Experiment) 


\section{Metode Pengolahan Data Awal}

Data yang didapatkan dari berupa data PT. Mitra Barito Sumber Sejahtera dalam bentuk file excel yang berupa data mentah yang sudah numerik, Rekapitulasi tersebut dilakukan dengan memperhatikan kebutuhan. Data yang digunakan adalah data dengan atribut penjualan harian mulai tahun 2009 sampai dengan tahun 2013. Data penjualan harian dari tahun 2009 sampai tahun 2012 dijadikan sebagai data training dan data penjualan harian tahun 2013 dijadikan sebagai data testing.

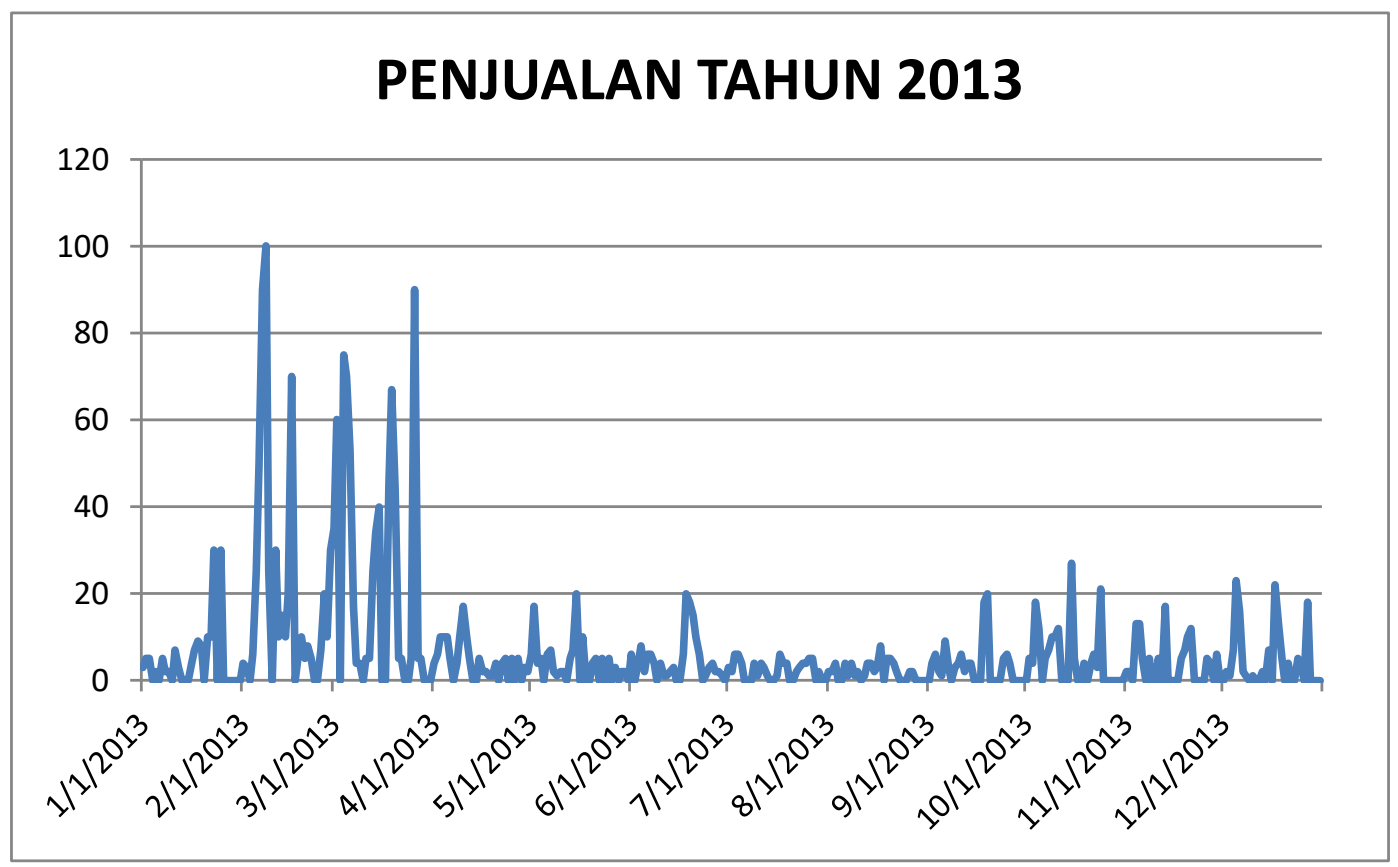

Gambar 2 Sample Diagram Penjualan 


\section{Metode Yang Diusulkan}

Metode yang diusulkan adalah metode Neural Network yang diharapkan memiliki factor kesalahan (RMSE) yang rendah dalam melakukan prediksi penjualan PT.Mitra Barito Sumber Sejahtera

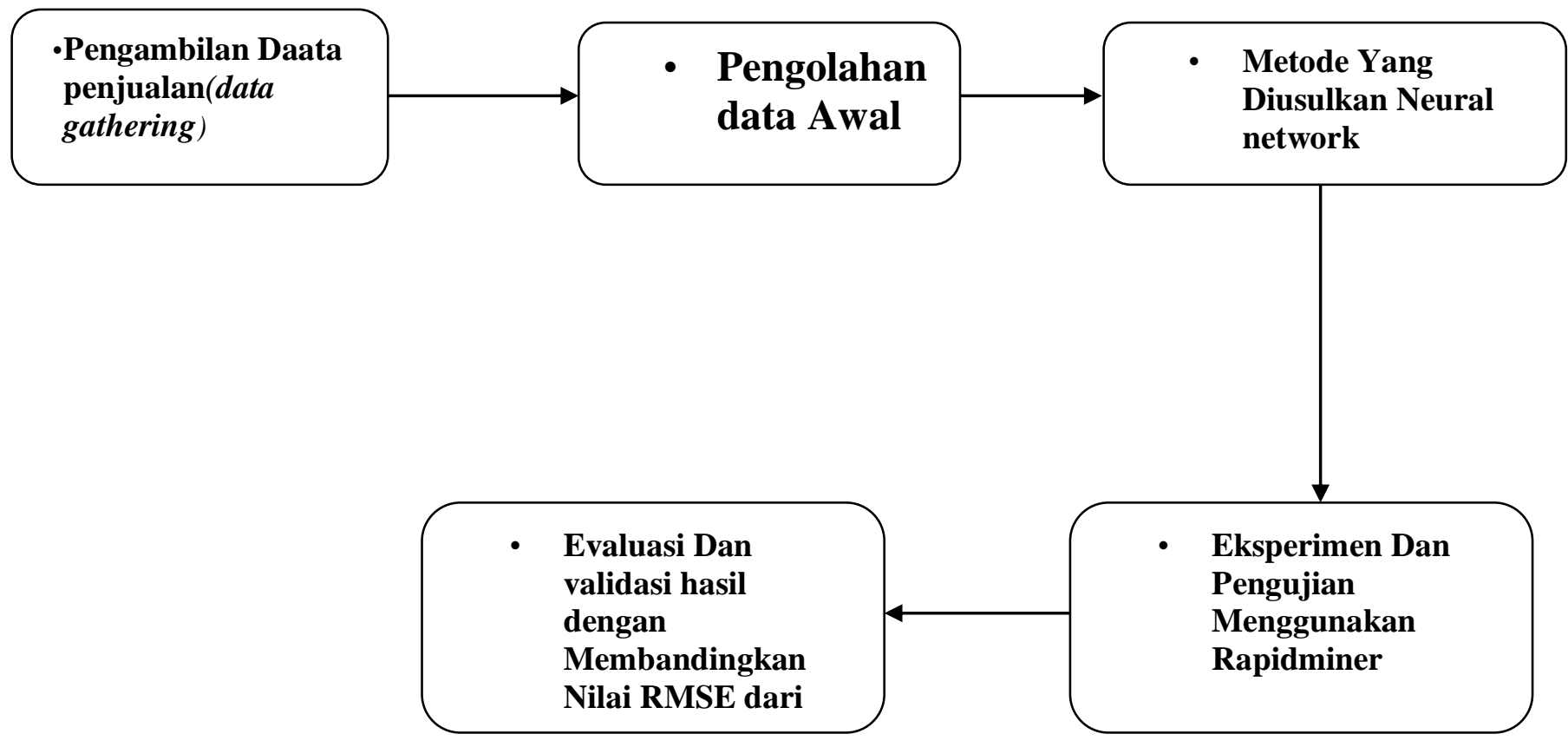

Gambar 3 Metode Yang Diusulkan

\section{Evaluasi dan Validasi}

Evaluasi dan validasi hasilakan diketahui setelah proses eksperimen dan pengujian dilaksanakan.pada tahap ini hasil dari eksperimen dan pengujian pada data menggunakan rapidminer dengan menerapkan metode neural network.

Penilaian performance prediksi atau pengukuran keakuratan dan keoptimalan suatu arsitektur jaringan yang digunakan dalam penelitian ini adalah faktor kesalahan RMSE(Root Mean Square Error). Semakin kecil nilai yang dihasilkan dari masing- masing parameter kinerja ini menyatakan semakin dekat nilai prediksi dengan nilai sebenarnya. Dengan demikian dapat diketahui keakuratan dari algoritma yang digunakan.

\section{HASIL PENELITIAN}

Eksperimen danPengujian Metode

Data 2009 sampai 20012 akan digunakan sebagai data training sedangkan data 20013 sebagai data testing.pengukuran kinerja dilakukan dengan menghitung ratarata error yang terjadi melalui bersaran Root Mean Square Error (RMSE).Semakin kecil 
nilai RMSE menyatakan semakin dekat dengan nilai prediksi sebenarnya.Dengan demikian dapat diketahui tingkat akurasi dari metode yang digunakan.

Data yg dimiliki adalah data univariate maka akan diubah menjadi data multivariate.bisa dilihat pada gambar dibawah

\begin{tabular}{|r|r|}
\hline $1 / 1 / 2009$ & 0 \\
\hline $1 / 2 / 2009$ & 1 \\
\hline $1 / 3 / 2009$ & 4 \\
\hline $1 / 4 / 2009$ & 0 \\
\hline $1 / 5 / 2009$ & 20 \\
\hline $1 / 6 / 2009$ & 20 \\
\hline $1 / 7 / 2009$ & 14 \\
\hline $1 / 8 / 2009$ & 15 \\
\hline $1 / 9 / 2009$ & 10 \\
\hline $1 / 10 / 2009$ & 1 \\
\hline $1 / 11 / 2009$ & 0 \\
\hline $1 / 12 / 2009$ & 2 \\
\hline $1 / 13 / 2009$ & 1 \\
\hline $1 / 14 / 2009$ & 0 \\
\hline $1 / 15 / 2009$ & 52 \\
\hline $1 / 16 / 2009$ & 0 \\
\hline $1 / 17 / 2009$ & 3 \\
\hline $1 / 18 / 2009$ & 0 \\
\hline
\end{tabular}

Table 1.

\section{Pengujian}

Eksperimen model Neural network berbasis seleksi menggunakan sampling data training 2009-2012 linier sampling sampling data.

\begin{tabular}{|c|c|}
\hline k-val & RMSE \\
\hline 2 & $0.501+/-0.002$ (mikro: $0.501+/-0.000)$ \\
\hline 3 & $0.501+/-0.002$ (mikro: $0.501+/-0.000)$ \\
\hline 4 & $0.501+/-0.002$ (mikro: $0.501+/-0.000)$ \\
\hline 5 & $0.501+/-0.002$ (mikro: $0.501+/-0.000)$ \\
\hline 6 & $0.501+/-0.002$ (mikro: $0.501+/-0.000)$ \\
\hline 7 & $0.501+/-0.002$ (mikro: $0.501+/-0.000)$ \\
\hline 8 & $0.501+/-0.002$ (mikro: $0.501+/-0.000)$ \\
\hline 9 & $0.501+/-0.002$ (mikro: $0.501+/-0.000)$ \\
\hline 10 & $0.501+/-0.002$ (mikro: $0.501+/-0.000)$ \\
\hline
\end{tabular}

Table 2 


\section{Hasil Eksperimen}

Hasil penelitian ini untuk melihat Root Mean Squered Error (RMSE) dari algoritma Neural Network adalah $\mathbf{0 . 5 0 1}$

\section{Kesimpulan}

Dari hasil penelitian tersebut dapat disimpulkan bahwa,algoritma Neural Network dapat memberikan hasil Root Mean Square Error (RMSE), berada di eksperimen yang menggunakan linier sampling data. data training 2009 sampai 2012 dan data testing tahun 2013 dengan K-Fold validasi 2 sampai 10 dengan hasil 0.501 .

\section{DAFTAR PUSTAKA}

[1] S. Zhang, M. Lei, Y. Dong, and W. He, "Adaptive neural network control of coordinated robotic manipulators with output constraint," IET Control Theory Appl., vol. 10, no. 17, pp. 2271-2278, 2016.

[2] F. D. Using, S. C. Test, and A. N. Networks, "Failure Diagnosis Using the State Chi-square Test," no. 3, pp. 32793283.

[3] P.-C. Chang, C.-H. Liu, C.-Y. Fan, and H.-C. Chang, "Data Clustering and Fuzzy Neural Network for Sales Forecasting in Printed Circuit Board Industry," 2007 IEEE Symp. Comput. Intell. Data Min., no. Cidm, pp. 107-113, 2007.

[4] D. Dovžan, V. Logar, and I. Škrjanc, "Solving the sales prediction problem with fuzzy evolving methods," IEEE Int. Conf. Fuzzy Syst., pp. 10-15, 2012.

[5] M. Program, S. Teknik, U. Maritim, R. Ali, and K. Kunci, "JARINGAN SYARAF TIRUAN BACKPROPAGATION ( Study Kasus : PDAM TIRTA KEPRI ) Ilham Aryudha Perdana," pp. 1-12, 2016.

[6] P. Linda, M. Situmorang, and G. Tarigan, "Peramalan Penjualan Produksi Teh 2014
Dengan Metode Arima Box-Jenkins," vol. 02, no. 03, pp. 253-266, 2014.

[7] J. T. Informasi, P. Teknik, I. Universitas, and D. Nuswantoro, "Prediksi Penjualan Air Minum Dalam Kemasan Menggunakan Jaringan Syaraf Tiruan Resilient," vol. 10, pp. 186-210, 2014.

[8] S. S. T. N. Diprediksi, "Kalman Filter Dengan Prediktor," no. September

2010, pp. 108-119, 2008.

[1] S. Zhang, M. Lei, Y. Dong, and W. He, "Adaptive neural network control of coordinated robotic manipulators with output constraint," IET Control Theory Appl., vol. 10, no. 17, pp. 2271-2278, 2016.

[2] F. D. Using, S. C. Test, and A. N. Networks, "Failure Diagnosis Using the State Chi-square Test," no. 3, pp. 32793283.

[3] P.-C. Chang, C.-H. Liu, C.-Y. Fan, and H.-C. Chang, "Data Clustering and Fuzzy Neural Network for Sales Forecasting in Printed Circuit Board Industry," 2007 IEEE Symp. Comput. Intell. Data Min., no. Cidm, pp. 107-113, 2007.

[4] D. Dovžan, V. Logar, and I. Škrjanc, "Solving the sales prediction problem with fuzzy evolving methods," IEEE Int. Conf. Fuzzy Syst., pp. 10-15, 2012.

[5] M. Program, S. Teknik, U. Maritim, R. Ali, and K. Kunci, "JARINGAN SYARAF TIRUAN

BACKPROPAGATION ( Study Kasus : PDAM TIRTA KEPRI ) Ilham Aryudha Perdana," pp. 1-12, 2016.

[6] P. Linda, M. Situmorang, and G. Tarigan, "Peramalan Penjualan Produksi Teh 2014 Dengan Metode Arima Box-Jenkins," vol. 02, no. 03, pp. 253-266, 2014.

[7] J. T. Informasi, P. Teknik, I. Universitas, and D. Nuswantoro, "Prediksi Penjualan Air Minum Dalam Kemasan Menggunakan Jaringan Syaraf Tiruan Resilient," vol. 10, pp. 186-210, 2014. 
[8] S. S. T. N. Diprediksi, "Kalman Filter Dengan Prediktor," no. September

2010, pp. 108-119, 2008.

[9] A. Wahana and A. R. Riswaya, "Perancangan Aplikasi Pengolahan Data Report Penjualan," J. Comput. Bisnis, vol. 8, no. 1, p. 25, 2014.

[10] V. N. Nore, "PERANCANGAN SISTEM INFORMASI PENJUALAN DAN PEMESANAN PRODUK BERBASIS WEB (Studi Kasus di CV. Richness Development Bandung)," pp. 1-111, 2013.

[11]W. K. Wardani, "DALAM UPAYA MENINGKATKAN PENGENDALIAN INTERN PERUSAHA AN ( Studi Kasus Pada PT Anugerah Cendrawasih Sakti Motor Malang )," vol. 12, no. 1, pp. 1-9, 2014.

[12]P. Li, Z. Tan, L. Yan, and K. Deng, "Time Series Prediction of Mining Subsidence Based on Genetic Algorithm Neural Network," 2011 Int. Symp. Comput. Sci. Soc., pp. 83-86, 2011.

[13]L. Thomas, "Discovery of Optimal Neurons and Hidden Layers in FeedForward Neural Network," 2016.

[14] J. Ling, I. putu E. N. Kencana, and T. B. Oka, "Analisis Sentimen Menggunakan Metode Naïve Bayes Classifier Dengan Seleksi Fitur Chi Square," E-Jurnal Mat., vol. 3, no. 3, pp. 92-99, 2014.

[15] T. Chai and R. R. Draxler, "Root mean square error (RMSE) or mean absolute error (MAE)? -Arguments against avoiding RMSE in the literature," Geosci. Model Dev., vol. 7, no. 3, pp. 1247-1250, 2014.

[16]C. Tan, "Financial Time Series Forecasting Using Improved Wavelet Neural Network Master ' s Thesis," 2009. 